
FciDioc

International Journal of Clinical \& Experimental Otolaryngology (IJCEO)

ISSN 2572-732X

\title{
Effect of Postoperative Montelukast on Chronic Rhinosinusitis with Polyposis Recurrence Following Functional Endoscopic Sinus Surgery
}

Research Article

Baradaranfar $\mathrm{MH}^{1}$, Azarnoosh $\mathrm{E}^{1}$, Dadgarnia $\mathrm{MH}^{1}$, Atighechi $\mathrm{S}^{1}$, Mirvakili A ${ }^{1}$, Baradaranfar $\mathrm{A}^{2}$, Vaziribozorg $\mathrm{S}^{*}$

${ }^{1}$ Department of Otolaryngology- Head and Neck Surgery, Otorhinolaryngology Research Center, Shahid Sadoughi University of Medical Sciences, Yazd, Iran.

${ }^{2}$ Otorhinolaryngology Research Center, Shahid Sadoughi University of Medical Sciences, Yazd, Iran.

\section{Abstract}

Introduction: The recurrence rate after surgery of chronic rhinosinusitis with nasal polyposis is high. Nasal and systemic steroids are effective in the decrease (reduction) of recurrence following surgery. Due to the complications of the corticosteroids, alternative treatments are studied, including leukotriene antagonists. In this study, the combination of the leukotriene receptor antagonist drug (montelukast) and intranasal steroid is compared with an intranasal steroid alone, in prevention of postoperative recurrence in patients with nasal polyposis.

Materials and Methods: This double-blind randomized clinical trial (RCT) was performed enrolling 30 chronic rhinosinusitis patients with polypoid undergoing the functional endoscopic sinus surgery. Patients were randomly divided into two groups. The patients in both groups were given fluticasone nasal spray and in the case and control group was used montelukast $(10 \mathrm{mg})$ and placebo tablet respectively for 6 weeks following the operation. 12 weeks after surgery, patients were evaluated regarding symptoms and sinonasal involvement was determined using endoscopy.

Results: Four patients were excluded due to non-cooperation in using drugs. There was no significant difference between the case and control groups regarding the prior history and preoperative symptoms and sinus involvement. After surgery, symptoms and sinus involvement improved significantly in both groups. Postoperative montelukast together with nasal fluticasone spray did not significantly differ from nasal fluticasone spray and placebo in decreasing the symptoms and polyps. Conclusion: The addition of montelukast to nasal steroid spray does not affect the postoperative relapse of symptoms and endoscopic findings of patients with chronic polypoid rhinosinusitis compared to the nasal steroid spray alone for the treatment.

Keywords: Nasal Polyposis; Chronic Rhinosinusitis; Leukotriene Antagonist; Montelukast; Endoscopic Sinus Surgery.

\section{Introduction}

Chronic rhinosinusitis is a chronic upper airway disease affecting the quality of life of the patients [1]. In 2006, 14 percent of adult Americans and $10.9 \%$ of Europeans had chronic rhinosinusitis [2]. Generally, the incidence of rhinosinusitis is 2 to 4 percent [3]. It may be polyposis or non polyposis. The etiology of the nasal polyposis is unknown. Like other chronic upper airway diseases, inflammatory mediators are involved. Leukotriens are among the mediators involved in nasal polyposis. They are the products of the Arachidonic Acid metabolism. They are of various types [4], including $\mathrm{LTc}_{4}$ that is an important mediator in the pathogenesis of the nasal polyposis [5]. Nasal polyps have many eosinophils and mast cells. These inflammatory cells produce a high level of the inflammatory leukotriens. Complex intracellular mechanisms lead to the release of these leukotriens. Administration of the leukotrien receptor antagonist drugs is effective in the treatment of the nasal polyps [5].

Some patients with chronic rhinosinusitis have other diseases

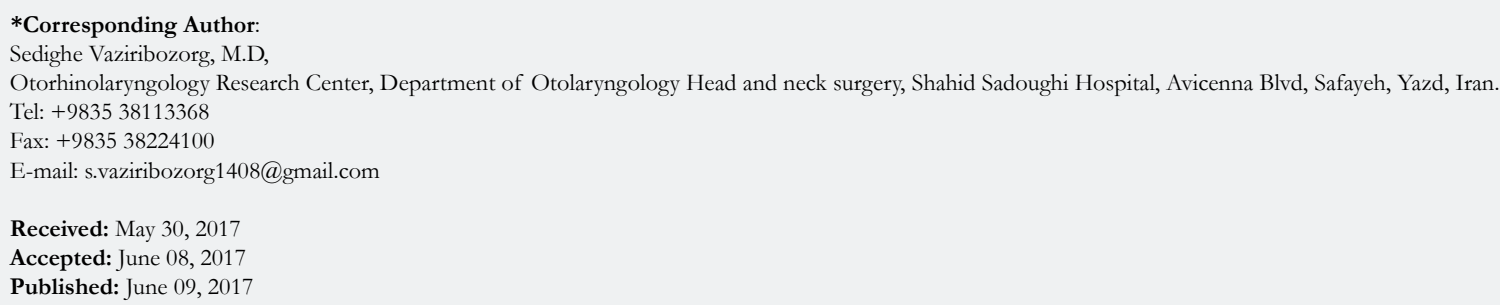


in the airways. For example, in the Sampter triad, patients have asthma, nasal polyposis, and allergy to the Aspirin [1].

The treatment of the nasal polyposis includes medical and surgical treatments. As a medical treatment, the combination of long-term use of the corticosteroid nasal sprays and short-term administration of oral corticosteroids improves the size of the polyp, symptoms, and nasal airflow [6].

Refractory patients to the medical treatments are candidates for surgery. The recurrence rate following surgery is high. The recurrence rate after functional endoscopic sinus surgery (FESS) was reported from $11.8 \%$ during 3 years to $51.2 \%$ during the 6 years [7]. So, medical treatment is recommended after the operation. Nasal and systemic steroids are effective in the decrease of the recurrence following surgery [2]. Due to complications of the corticosteroids, alternative treatments are studied, including leukotriene antagonists such as zafirlukast, montelukast, and zileuton. It is documented that these drugs can be used in patients who do not tolerate postoperative nasal steroids [8].

The postoperative recurrence rate is high even in patients who receive local steroids. In this study, the combination of the leukotriene receptor antagonist drug montelukast and intranasal steroid is compared with an intranasal steroid alone in prevention of postoperative recurrence of nasal polyposis patients.

\section{Materials and Methods}

This study was a double-blind randomized clinical trial that performed on patients with chronic polypoid rhinosinusitis between October 2013 and June 2014. The study was approved by the local research ethics committee. The patients had confirmed bilateral nasal polyposis documented by endoscopy and CT scan prior to the FESS. Exclusion criteria included secondary revision patients, use of oral steroid or montelukast during 1 month prior to surgery, patients who were missed during follow-up, or those who did not use the drug with the prescribed dose.

Functional endoscopic sinus surgery was performed on thirty patients with nasal polyposis by a surgeon. Patients were randomly divided into two groups. The case group patients used nasal fluticasone spray and montelukast $(10 \mathrm{mg})$ tablet once daily and the control group patients received nasal fluticasone spray and a placebo tablet for 6 weeks following FESS. Frequent postoperative visits were performed for monitoring of drug complications. 12 weeks after surgery, patients were evaluated regarding two types of criteria: A- symptom score of facial pain, rhinorrhea, olfactory problem, and nasal obstruction as 1 for no problem, 2 for mild, 3 for moderate, and 4 for severe problem; B- involvement of maxillary, anterior ethmoid, posterior ethmoid, and sphenoid sinuses, or frontal recess determined endoscopically by one surgeon as 0 for no polyp and 1 for presence of polyp.

\section{Results}

Four patients were excluded due to lack of cooperation on drug use. Of the remaining 26 patients, 13 were in the case group. The patients were 20 to 56 years. Nine patients $(34.6 \%)$ were female and 17 patients $(65.4 \%)$ were male. Three patients $(11.5 \%)$ had history of asthma, $9(34.6 \%)$ had allergy and 3 cases $(11.5 \%)$ had both. There was no significant difference between the case and control groups regarding the past history (Mann-Whitney U, NS; Table 1). Facial pain, rhinorrhea, olfactory problem, and nasal obstruction had no significant difference between the case and control groups (Table 2). Also, both groups had no significant difference regarding the involvement of maxillary, anterior ethmoid, posterior ethmoid, and sphenoid sinuses, or frontal recess (Table 3).

Following functional endoscopic sinus surgery, symptoms were improved significantly generally and in each group except for facial pain in the control group (Table 4). Sinus involvement in endoscopy was improved significantly in all groups, too (Table 5). Postoperative montelukast together with nasal fluticasone spray did not differ significantly from nasal fluticasone spray and placebo in decreasing the symptoms and polyps (Table 6). No drug-related complication was observed in postoperative visits.

\section{Discussion}

In this study, all chronic polypoid rhinosinusitis patients that were undergone functional endoscopic sinus surgery received nasal steroid spray. Steroids are one of the most principal treatments of nasal polyposis and are recommended to continue after the operation for long periods [9]. In this study, the case group received nasal steroid spray together with montelukast. Montelukast is a leukotriene antagonist. It is used in the inflammatory diseases of the upper airways. It has some side effects including gastrointestinal disorders, headache, sleep disorder, hypersensitivity reaction, bleeding tendency, and Churg-Straus syndrome [10]. Because it causes bleeding tendency, montelukast was used in this study 5 days after operation. No side effect was seen in the studied cases.

This study was planned as the recommendation of the metaanalysis performed by Wentzel et al., They had recommended a study about the effect of the montelukast together with steroid spray [8]. In our study, both the case and control groups demonstrated significant improvement in the symptoms and endoscopy findings but there was no statistically significant difference between the two groups. In the study that performed by Mostafa, patients with asthma and nasal polyposis were divided in

Table 1. Past History of the Studied Cases.

\begin{tabular}{|c|c|c|c|}
\hline \multirow{2}{*}{ Past History } & \multicolumn{2}{|c|}{ Group } & \multirow{2}{*}{ Total } \\
\cline { 2 - 3 } & Case & Control & \\
\hline Asthma & 2 & 1 & 3 \\
\hline Allergy & 5 & 4 & 9 \\
\hline Asthma \& Allergy & 1 & 2 & 3 \\
\hline None & 5 & 6 & 11 \\
\hline
\end{tabular}


Table 2. Comparison of Preoperative Symptoms in Two Groups.

\begin{tabular}{|c|c|c|c|c|c|}
\hline \multirow{2}{*}{ Symptom } & \multirow{2}{*}{ Condition } & \multicolumn{2}{|c|}{ Group } & \multirow{2}{*}{ Total } & \multirow{2}{*}{ Significance } \\
\hline & & Case & Control & & \\
\hline \multirow{4}{*}{ Facial pain } & No & 10 & 8 & 18 & \multirow{4}{*}{0.448} \\
\hline & Mild & 2 & 4 & 6 & \\
\hline & Moderate & 1 & 1 & 2 & \\
\hline & Severe & 0 & 0 & 0 & \\
\hline \multirow{4}{*}{ Rhinorrhea } & No & 0 & 0 & 0 & \multirow{4}{*}{0.751} \\
\hline & Mild & 4 & 2 & 6 & \\
\hline & Moderate & 6 & 9 & 15 & \\
\hline & Severe & 3 & 2 & 5 & \\
\hline \multirow{4}{*}{ Olfactory problem } & No & 0 & 0 & 0 & \multirow{4}{*}{0.801} \\
\hline & Mild & 4 & 4 & 8 & \\
\hline & Moderate & 6 & 7 & 13 & \\
\hline & Severe & 3 & 2 & 5 & \\
\hline \multirow{4}{*}{ Nasal obstruction } & No & 0 & 0 & 0 & \multirow{4}{*}{0.825} \\
\hline & Mild & 2 & 3 & 5 & \\
\hline & Moderate & 6 & 5 & 11 & \\
\hline & Severe & 5 & 5 & 10 & \\
\hline
\end{tabular}

Table 3. Comparison of Preoperative Sinus Involvement in Two Groups.

\begin{tabular}{|c|c|c|c|c|c|}
\hline \multirow{2}{*}{ Sinus } & \multirow{2}{*}{ Condition } & \multicolumn{2}{|c|}{ Group } & \multirow{2}{*}{ Total } & \multirow{2}{*}{ Sig. } \\
\cline { 2 - 6 } & & Case & Control & & \\
\hline \multirow{2}{*}{ Maxillary } & Clear & 8 & 7 & 15 & 0.697 \\
\cline { 2 - 6 } & Involved & 5 & 6 & 11 & \\
\hline \multirow{2}{*}{ Anterior ethmoid } & Clear & 0 & 0 & 0 & 1.000 \\
\cline { 2 - 6 } & Involved & 13 & 13 & 26 & \\
\hline \multirow{2}{*}{ Posterior ethmoid } & Clear & 1 & 3 & 4 & 0.286 \\
\cline { 2 - 6 } & Involved & 12 & 10 & 22 & \\
\hline \multirow{2}{*}{ Sphenoid } & Clear & 7 & 5 & 12 & 0.440 \\
\cline { 2 - 6 } & Involved & 6 & 8 & 14 & \\
\hline \multirow{2}{*}{ Frontal recess } & Clear & 0 & 0 & 0 & 1.000 \\
\cline { 2 - 6 } & Involved & 13 & 13 & 26 & \\
\hline
\end{tabular}

Table 4. Comparison of Preoperative and Postoperative Symptoms.

\begin{tabular}{|c|c|c|c|c|c|c|c|}
\hline \multirow{3}{*}{ Symptom } & \multirow{3}{*}{ Condition } & \multicolumn{4}{|c|}{ Group } & \multirow{2}{*}{\multicolumn{2}{|c|}{ Total }} \\
\hline & & \multicolumn{2}{|l|}{ Case } & \multicolumn{2}{|l|}{ Control } & & \\
\hline & & Pre op - Post op & Sig. & Pre op - Post op & Sig. & Pre op - Post op & Sig. \\
\hline \multirow{4}{*}{ Facial pain } & No & $10-12$ & \multirow{4}{*}{0.034} & $8-13$ & \multirow{4}{*}{0.083} & $18-25$ & \multirow{4}{*}{0.007} \\
\hline & Mild & $2-1$ & & $4-0$ & & $6-1$ & \\
\hline & Moderate & $1-0$ & & $1-0$ & & $2-0$ & \\
\hline & Severe & $0-0$ & & $0-0$ & & $0-0$ & \\
\hline \multirow{4}{*}{ Rhinorrhea } & No & $0-6$ & \multirow{4}{*}{0.001} & $0-8$ & \multirow{4}{*}{0.001} & $0-14$ & \multirow{4}{*}{0.000} \\
\hline & Mild & $4-5$ & & $2-4$ & & $6-9$ & \\
\hline & Moderate & $6-2$ & & $9-1$ & & $15-3$ & \\
\hline & Severe & $3-0$ & & $2-0$ & & $5-0$ & \\
\hline \multirow{4}{*}{ Olfactory problem } & No & $0-2$ & \multirow{4}{*}{0.003} & $0-3$ & \multirow{4}{*}{0.005} & $0-5$ & \multirow{4}{*}{0.000} \\
\hline & Mild & $4-8$ & & $4-8$ & & $8-16$ & \\
\hline & Moderate & $6-3$ & & $7-2$ & & $13-5$ & \\
\hline & Severe & $3-0$ & & $2-0$ & & $5-0$ & \\
\hline \multirow{4}{*}{ Nasal obstruction } & No & $0-6$ & \multirow{4}{*}{0.001} & $0-10$ & \multirow{4}{*}{0.001} & $0-16$ & \multirow{4}{*}{0.000} \\
\hline & Mild & $2-7$ & & $3-3$ & & $5-10$ & \\
\hline & Moderate & $6-0$ & & $5-0$ & & $11-0$ & \\
\hline & Severe & $5-0$ & & $5-0$ & & $10-0$ & \\
\hline
\end{tabular}


Table 5. Comparison of Preoperative and Postoperative Sinus Involvement.

\begin{tabular}{|c|c|c|c|c|c|c|c|}
\hline \multirow{3}{*}{ Sinus } & \multirow{3}{*}{ Condition } & \multicolumn{4}{|c|}{ Group } & \multirow{2}{*}{\multicolumn{2}{|c|}{ Total }} \\
\hline & & \multicolumn{2}{|l|}{ Case } & \multicolumn{2}{|l|}{ Control } & & \\
\hline & & Pre op-post op & Sig. & Pre op-post op & Sig. & Pre op-post op & Sig. \\
\hline \multirow{2}{*}{ Maxillary } & Clear & $7-12$ & \multirow{2}{*}{0.025} & $8-13$ & \multirow{2}{*}{0.025} & $15-25$ & \multirow{2}{*}{0.002} \\
\hline & Involved & $6-1$ & & $5-0$ & & $11-1$ & \\
\hline \multirow{2}{*}{ Anterior ethmoid } & Clear & $0-11$ & \multirow{2}{*}{0.001} & $0-10$ & \multirow{2}{*}{0.002} & $0-21$ & \multirow{2}{*}{0.000} \\
\hline & Involved & $13-2$ & & $13-3$ & & $26-5$ & \\
\hline \multirow{2}{*}{ Posterior ethmoid } & Clear & $3-12$ & \multirow{2}{*}{0.003} & $1-12$ & \multirow{2}{*}{0.001} & $4-24$ & \multirow{2}{*}{0.000} \\
\hline & Involved & $10-1$ & & $12-1$ & & $22-2$ & \\
\hline \multirow{2}{*}{ Sphenoid } & Clear & $5-13$ & \multirow{2}{*}{0.005} & $7-13$ & \multirow{2}{*}{0.014} & $12-26$ & \multirow{2}{*}{0.000} \\
\hline & Involved & $8-0$ & & $6-0$ & & $14-0$ & \\
\hline \multirow{2}{*}{ Frontal recess } & Clear & $0-11$ & \multirow{2}{*}{0.001} & $0-10$ & \multirow{2}{*}{0.002} & $0-21$ & \multirow{2}{*}{0.000} \\
\hline & Involved & $13-2$ & & $13-3$ & & $26-5$ & \\
\hline
\end{tabular}

Table 6. Comparison of postoperative montelukast together and fluticasone spray with nasal fluticasone spray and placebo in decreasing the symptoms and polyps.

\begin{tabular}{|c|c|}
\hline Symptom or sinus involvement & Significance (Mann-Whitney U) \\
\hline Facial pain & 0.356 \\
\hline Rhinorrhea & 0.108 \\
\hline Olfactory problem & 0.750 \\
\hline Nasal obstruction & 0.353 \\
\hline Maxillary sinus & 1.000 \\
\hline Anterior ethmoidsinus & 0.626 \\
\hline Posterior ethmoidsinus & 0.361 \\
\hline Sphenoidsinus & 0.440 \\
\hline Frontal recess & 0.626 \\
\hline
\end{tabular}

two groups. One group received corticosteroid spray and the other received montelukast for one year. Both groups had remarkable improvement; but the two groups were not significantly different [11]. Leukotriene antagonist caused more improvement in some symptoms as itching, posterior nasal discharge, and headache. In that study, leukotriene antagonist led to statistically significant improvement in rhinorrhea compared with the control group but no other symptom.

Vuralkan et al., divided the operated nasal polyposis patients into two groups. One group received mometasone spray and the other montelukast for 6 months. Both groups demonstrated significant improvement in the symptoms and CT scan and peripheral blood eosinophil but the two groups were not statistically different; although the improvement in the smelling was better in the case group [12].

Stewart treated the nasal polyposis patients with oral steroid for 14 days. After treatment, the case group received montelukast together with budesonide spray for 8 weeks and the control group received budesonide spray. Both groups had remarkable improvement; but the difference between the two groups was not significant. The improvement was more significant in the symptoms as headache, facial pain, and sneezing. There was a tendency for the symptoms to recur after termination of the drugs. No significant change in the quality of life was observed [13].

Other non-controlled studies have evaluated the effect of the montelukast on the nasal polyposis. In the study performed by Kieff, nasal polyposis patients received montelukast and steroid spray for 3 months. Significant improvement in symptoms and local eosinophils was seen [14].

Based on the above mentioned studies, after the operation for the patients with nasal polyposis, the group who received nasal steroid spray had similar results regarding the improvement of the symptoms as the group who received montelukast. So, we can administer the oral drug montelukast to the patients who do not prefer corticosteroid spray or have had the complications of its use. On the basis of our study, montelukast addition to the steroid spray has no additive use compared to the steroid spray alone.

\section{Conclusion}

Addition of montelukast to nasal steroid spray does not affect the postoperative relapse of the symptoms and endoscopy findings of patients with nasal polyposis compared to the nasal steroid spray alone.

\section{References}

[1]. Mohammad Naeimi, Elham Azarnoosh, Mohammad Sadegh Javedani Gholparvar, Mohammad Reza Naeimi ( 2013) Histopathologic Relationship Between Ethmoid Sinus and Ipsilateral Middle Turbinate in Non-Polypose Chronic Sinusitis by FESS. Indian J Otolaryngol Head Neck Surg. 65(2): 324- 328.

[2]. Bardaranfar MH, Ranjbar Z, Dadgarnia MH, Atighechi S, Mirvakili A, et al.( 2014) The effect of an absorbable gelatin dressing impregnated with triamcinolone within the olfactory cleft on polypoid rhinosinusitis smell disor- 
ders. Am J Rhinol Allergy.28(2): 172-5.

[3]. Baradaranfar MH, Ahmadi ZS, Dadgarnia MH, Bemanian MH, Atighechi S, et al.(2014) Comparison of the effect of endoscopic sinus surgery versus medical therapy on olfaction in nasal polyposis. Eur Arch Otorhinolaryngol. 271(2): 311-6.

[4]. Nonaka M1, Sakanushi A, Kusama K, Ogihara N, Yagi T (2010) One-year evaluation of combined treatment with an intranasal corticosteroid and montelukast for chronic rhinosinusitis associated with asthma. J Nippon Med Sch. 77(1): 21-8.

[5]. Di Capite J, Nelson C, Bates G, Parekh AB (2009) Targeting Ca2+ releaseactivated $\mathrm{Ca} 2+$ channel channels and leukotriene receptors provides a novel combination strategy for treating nasal polyposis. J Allergy Clin Immunol. 124(5): 1014-21.

[6]. Kirtsreesakul V, Wongsritrang K, Ruttanaphol S (2012) Does oral prednisolone increase the efficacy of subsequent nasal steroids in treating nasal polyposis? Am J Rhinol Allergy. 26(6): 455-62.

[7]. Schäper C, Noga O, Koch B, Ewert R, Felix SB, et al., (2011) Anti-inflammatory properties of montelukast, a leukotriene receptor antagonist in patients with asthma and nasal polyposis. J Investig Allergol Clin Immunol. 21(1): 51-8.
[8]. Jennifer L. Wentzel, Zachary M Soler, Kristen DeYoung, Shaun A Nguyen, Shivangi Lohia, et al., (2013) Leukotriene antagonists in nasal polyposis: a meta-analysis and systematic review. Am J Rhinol Allergy. 27(6): 482- 489.

[9]. Lildholdt T, Rundcrantz H, Lindqvist N (1995) Efficacy of topical corticosteroid powder for nasal polyps: a double-blind, placebo-controlled study of budesonide. Clin Otolaryngol Allied Sci. 20(1): 26-30.

[10]. Hon KL, Leung TF, Leung AK (2014) Clinical effectiveness and safety of montelukast in asthma. What are the conclusions from clinical trials and meta-analyses?. Drug Des Devel Ther. 8: 839-50.

[11]. Mostafa BE, Abdel Hay H, Mohammed HE, Yamani M (2005) Role of leukotriene inhibitors in the postoperative management of nasal polyps. ORL J Otorhinolaryngol Relat Spec. 67(3): 148-53.

[12]. Vuralkan E, Saka C, Akin I, Hucumenoglu S, Unal BU, et al., (2012) Comparison of montelukast and mometasone furoate in the prevention of recurrent nasal polyps. Ther Adv Respir Dis. 6(1): 5-10.

[13]. Stewart RA, Ram B, Hamilton G, Weiner J, Kane KJ (2008) Montelukast as an adjunct to oral and inhaled steroid therapy in chronic nasal polyposis. Otolaryngol Head Neck Surg.139(5): 682-7.

[14]. Kieff DA, Busaba NY (2005) Efficacy of montelukast in the treatment of nasal polyposis. Ann Otol Rhinol Laryngol. 114(12): 941-5. 